\title{
Elucidation of the Structure of Organic Compounds by Thermal Fragmentation
}

\section{Journal Article}

\section{Author(s):}

Simon, W.; Kriemler, P.; Voellmin, J. A.; Steiner, H.

Publication date:

1967

\section{Permanent link:}

https://doi.org/10.3929/ethz-b-000422792

\section{Rights / license:}

In Copyright - Non-Commercial Use Permitted

\section{Originally published in:}

Journal of Chromatographic Science 5(2), https://doi.org/10.1093/chromsci/5.2.53 


\title{
Elucidation of the Structure of Organic Compounds by Thermal Fragmentation
}

\author{
by W. Simon, P. Kriemler, J. A. Voellmin, and H. Steiner, Department for Organic Chemistry, \\ Swiss Federal Institute of Technology, Zurich, Switzerland
}

\begin{abstract}
The thermal fragmentation of organic compounds is described using a technique in which the sample is coated on a ferromagnetic conductor. This conductor can be reproducibly heated to an accurately defined temperature (Curie point) in 20 to 30 milliseconds. Techniques are described to study fragmentation mechanisms.
\end{abstract}

A great variety of fragmentation techniques are in widespread use in organic chemistry for structural analysis. Such a reaction has been used, for instance, in 1927 which led to the first correct skeleton for steroids (Figure 1) (1). Pyrolysis as well as reaction gas chromatography have similar potentialities in the elucidation of the structure of organic compounds. In pyrolysis gas chromatography the samples are thermally fragmented in a stream of an inert carrier gas, and the reaction products are passed directly into a gas chromatography column where they are separated (2). It has been shown on different occasions that the pyrolysis gas chromatogram may be used as a finger- print io: the material studied (3, 4.). Under certain conditions the structure of the fragments obtained correlates closely with the structure of the starting material (5). The successful use of pyrolysis gas chromatography in the structural elucidation of organic compounds and in the qualitative and quantitative analysis of mixtures is possible under the following ideal conditions (5-8).

a) The fragmentation of the sample must be carried out at such a high dilution and the fragments so quickly stabilized that no undesirable recombination reactions can occur.

b) The sample must be heated to a constant pyrolysis temperature as quickly and as reproducibly as possible.

c) The pyrolysis temperature must not be too high, since uncharacteristic fragments (methane, carbon, hydrogen) may otherwise b? formed preferentially.

If conditions (a) to (c) are satisfied, the fragments should be closely related to the structure of the original compound, and the py- rolysis gas chromatogram of a mixture can be deduced by adding together the signals of the pyrolysis chromatograms of the individual components.

A pyrolysis unit that operates close to the ideal conditions has been described earlier $(5,7)$ (see Figure 2). A thin layer of the sample under investigation is coated on a ferromagnetic conductor $(5$ in Figure 2) which is warmed up in 20-30 milliseconds to a constant temperature using high frequency induction heating. The arrangement can be attached to inlet systems of standard gas chromatographs. The po" in a high frequency induction coil depends on the magnetic field inside the coil, the radius, specific resistance, and magnetic permeability of the conductor, as well as the frequency applied (5). Owing to the dras'ic change in the magnetic permeability of the ferromagnetic conductor at the Curie point, the energy input drops at that temperature. If the energy loss of the conductor above the Curie point is equal or larger than the energy up-
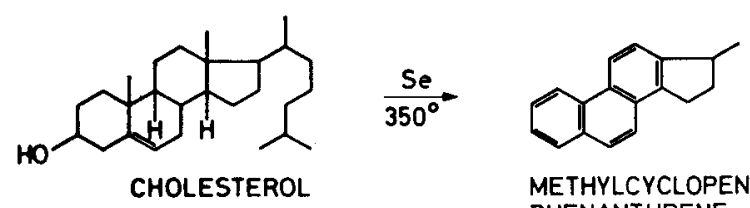

METHYLCYCLOPENTENO PHENANTHRENE (DIELS HYDROCARBON)

Figure 1. Selenium Dehydrogenation of Steroids

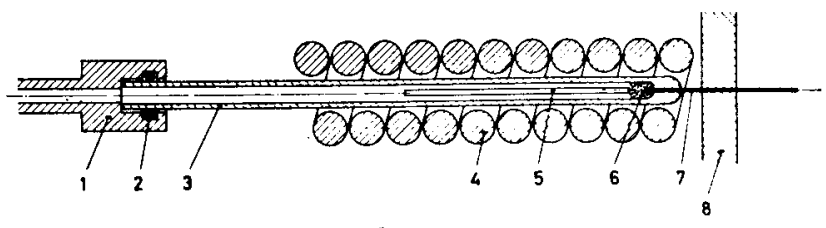

$2 \mathrm{~cm}$

Figure 2. Pyrolysis Unit (10). 1-Carrier gas connector; 2-O-ring; 3-Glass capillary; 4-High frequency induction coil (copper) connected to an oscillator working at $0.45 \mathrm{MHz} ; 5-$ Ferromagnetic conductor (wire: $0.5 \times 20 \mathrm{~mm}$ ); 6-Sintered glass beads; 7-Platinum iridium capillary $0.3 \mathrm{~mm}$ inner diameter); 8-Serum cap of inlet system of a gas chromatograph. 
take from the field, the conductor will warm up only to that temperature. When an oscillator with a certain range of frequencies and a conductor of a limited range of diameters is used, the final temperature (Curie temperature) depends only on the ferromagnetic material and is independent of any fluctuations in experimental conditions (5). In Figure 3 warm up curves are given for different commercially available ferromagnetic conductors (5). By increasing the radius of the conductor, the energy uptake above the Curie point may become larger than the energy losses. In this case the warm up will not stop at the Curie point and will be slower for a given oscillator due to the higher mass of the conductor of larger diameter (Figure 4). So far no catalytic effects have been observed when using ferromagnetic conductors of different composition (8). The behaviour of the conductors in the thermal fragmentation was not changed even by coating them with gold or platinum. Usually the yield in the characteristic fragments shows an optimum at about $700^{\circ} \mathrm{C}$ in agreement with results obtained by the filament technique (9) (Figure 5). Since the dead volume of the pyrolysis zone is small $(\geqslant 5 \mu \mathrm{l})$ and the pyrolysis time short, GC systems of high resolution may be used. A pyrolysis gas chromatogram of 5 $\mu \mathrm{g}$ of methionine is given in Figure

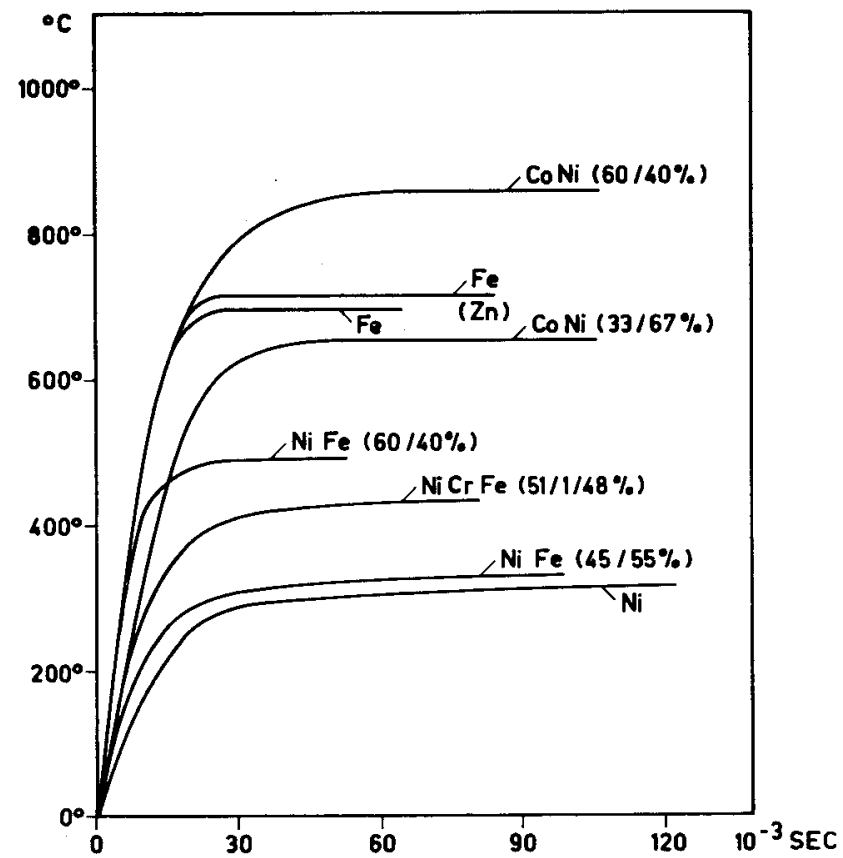

Figure 3. Warm up Curves for Different Ferromagnetic Conductors

(Diameter: 0.5-0.6 mm; Oscillator Frequency: $0.45 \mathrm{MHz}$ )

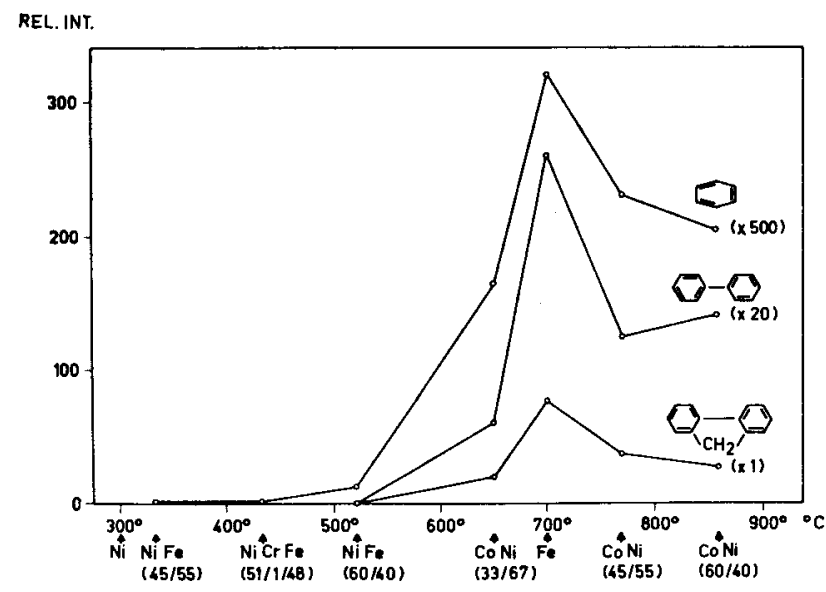

Figure 5. Yield of Fragments in the Pyrolysis of the Sodium Salt of Benzoic Acid
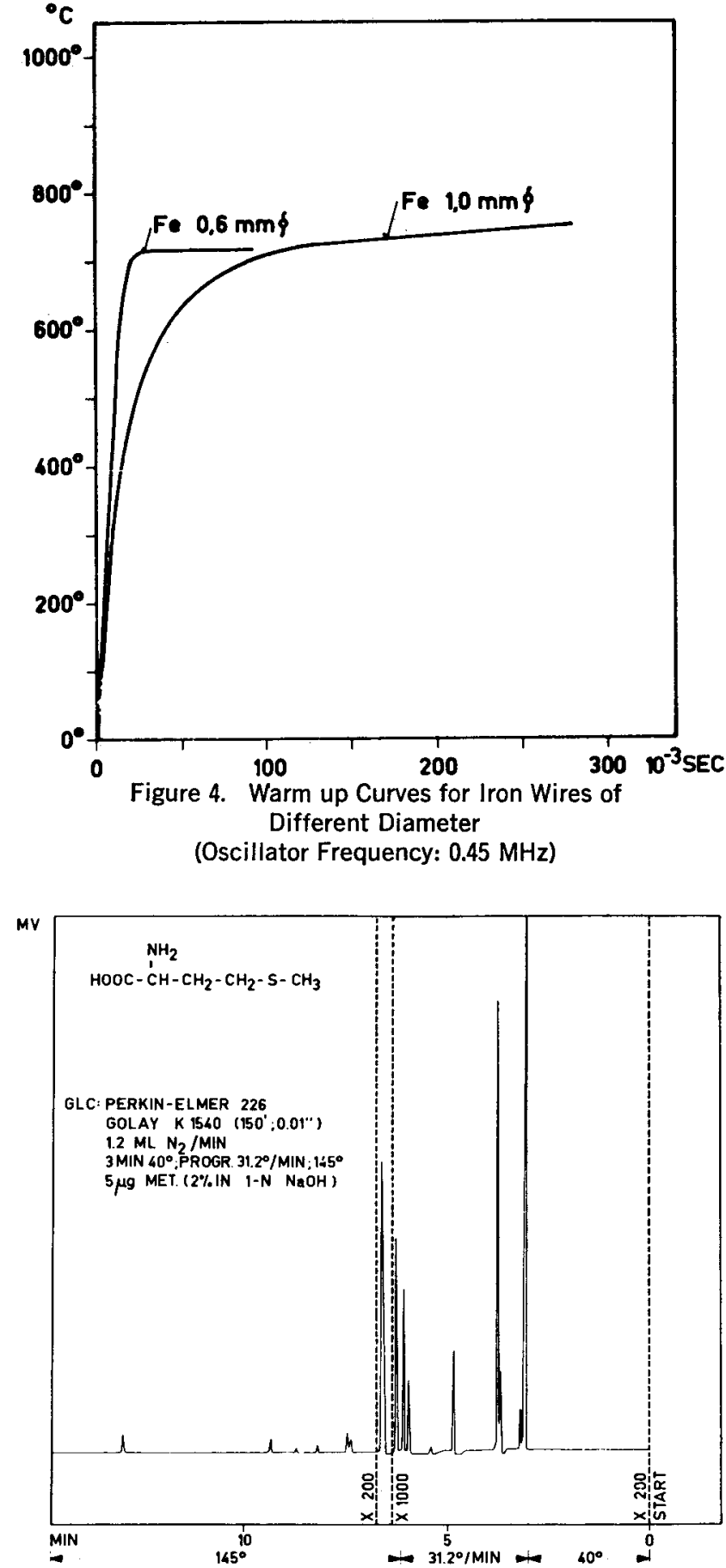

Figure 6. Pyrolysis Gas Chromatogram of $5 \mu \mathrm{g}$ of Methionine (Ferromagnetic conductor $\mathrm{Fe}(\mathrm{Zn}), \sim 700^{\circ} \mathrm{C} ; 20 \times 0.5 \mathrm{~mm}$ ) 


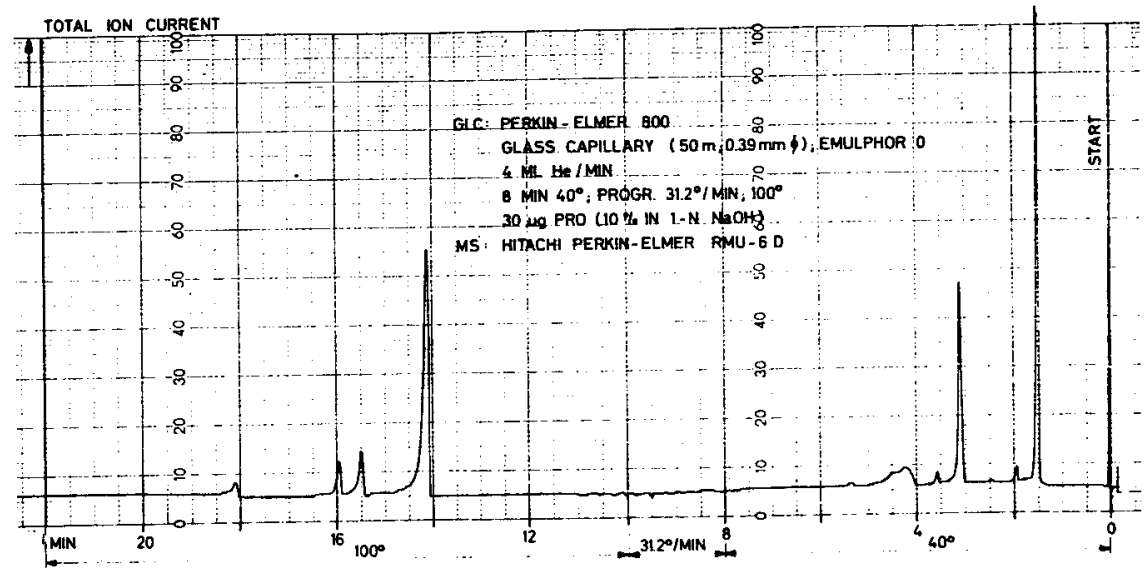

Figure 7. Pyrolysis Gas Chromatogram of Proline

(Ferromagnetic conductor: $\mathrm{Fe}(\mathrm{Zn}) ; 20 \times 0.5 \mathrm{~mm}$; end temperature: $\sim 700^{\circ} \mathrm{C}$ )

6. It was obtained using a tubular column without a sample splitter.

Since the thermal fragmentation is preferably performed on samples in the $\mu \mathrm{g}$ range [see (a) above], mass spectrometry is the method of choice for the determination of the structure of the pyrolysis products. A detailed description of a direct instrumental combination of thermal fragmentation (TF)/gas chromatography (GC)/mass spectrome- try (MS) in which fragments as small as 0.01 to $0.001 \mu \mathrm{g}$ may be identified has been given elsewhere (10, 11). A typical pyrolysis gas chromatogram obtained with such an arrangement is given in Figure 7. The mass spectrometer is used as the GC detector, the total ion current being recorded.

To obtain information about the mechanism of the pyrolysis described, a program to study simple molecules is in progress in our laboratory. A schematic pyrolysis gas chromatogram for the sodium salt of benzoic acid $(200 \mu \mathrm{g})$ as obtained in the TF/GC/MS combination, including the structure of the fragments, is given in Figure 8. It is obvious that undesirable recombination reactions have occurred. This is not surprising since even if the distribution of the sample on the surface of the wire were uniform, the thickness of the film would be of the order of 10,000 molecules (5). The probability for recombination reactions decreases with decreasing sample size. Thus, the relative yield of biphenyl decreases as the quantity of sodium benzoate on the ferromagnetic wire is reduced (Figure 9). A reduction of the amount of benzoic acid from 20 to $2 \mu \mathrm{g}$ gives a reduction in the relative amount of biphenyl formed of about two. Using about $0.2 \mu \mathrm{g}$ benzoic acid, biphenyl can no longer be detected; the amount formed must have been reduced at least 1,000 times. It has been assumed earlier (5) that the decrease in the yield of benzene with increasing sample size is probably due to the

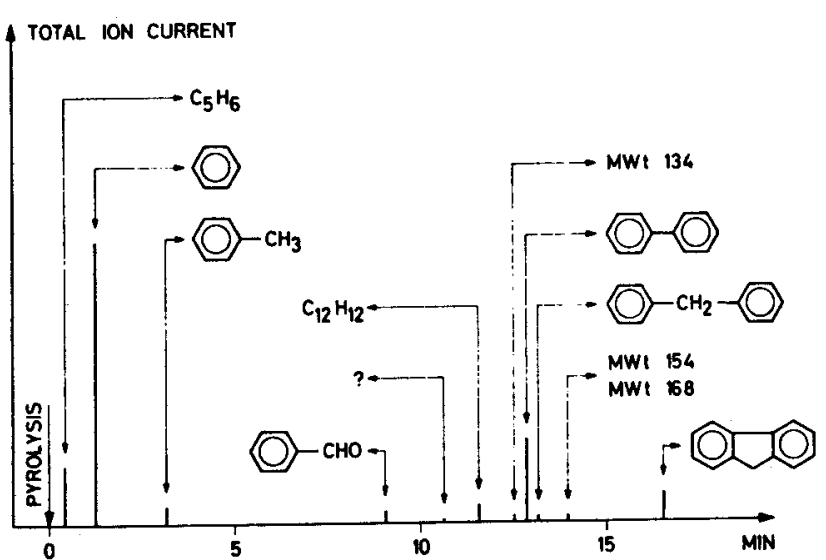

Figure 8. Thermal Fragmentation of $200 \mu \mathrm{g}$ of Benzoic Acid (Sodium Salt)

(Ferromagnetic conductor: $\mathrm{Fe}(\mathrm{Zn}) ; 20 \times 0.5 \mathrm{~mm}$; end

GLC: Perkin-EImer 800 temperature: $\sim 700^{\circ} \mathrm{C}$ )

Open tubular column $50 \mathrm{ft}$; 0.02 in.; Carbowax K 1540

$10 \mathrm{ml} \mathrm{He} / \mathrm{Min}$.

$3.7 \mathrm{~min} .50^{\circ} \mathrm{C}$; Prog. $16.7^{\circ} \mathrm{C} / \mathrm{min}$; $180^{\circ} \mathrm{C}$.

MS: Hitachi Perkin-Elmer RMU-6D

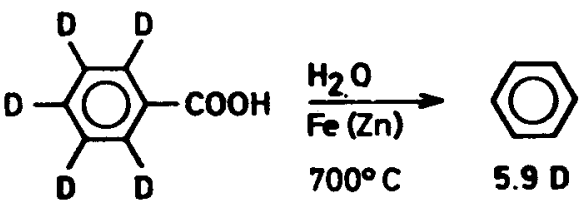

$85 \% D_{6}$ $15 \% D_{5}$

Figure 10. Thermal Fragmentation of Benzoic Acid-d,

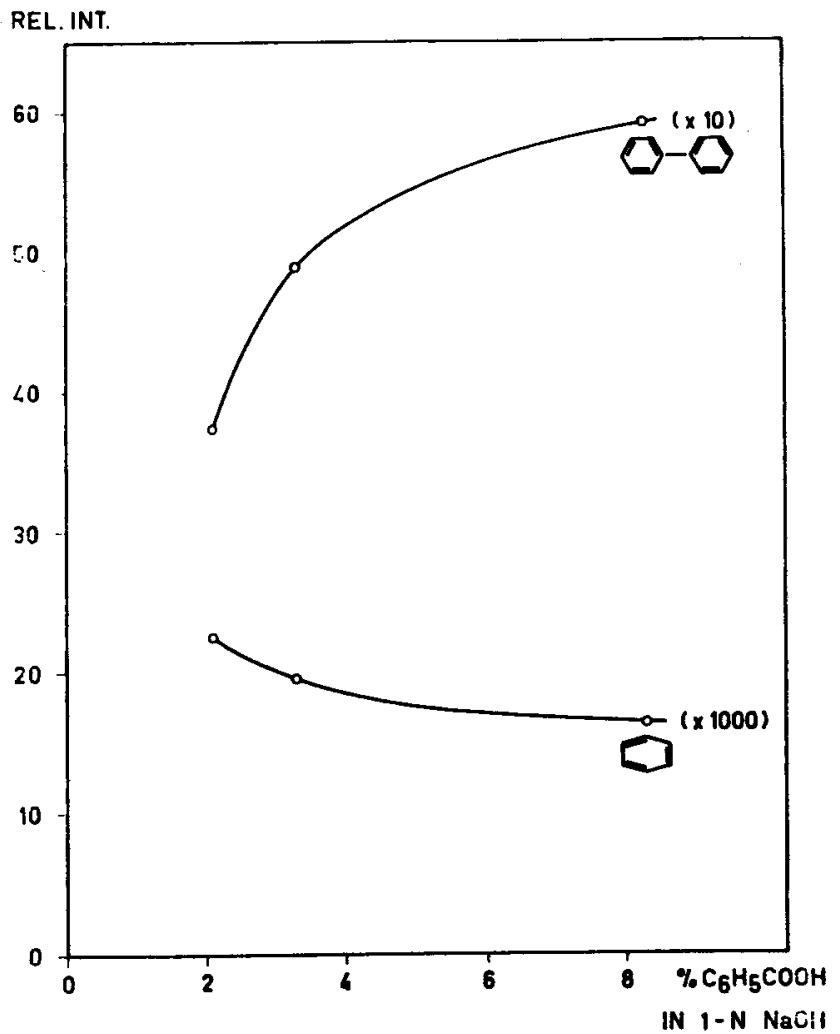

Figure 9. Relative Yield in the Formation of Biphenyl and Benzene (5)

(Pyrolysis of Sodium Benzoate; Ferromagnetic conductor: $\left.\mathrm{Fe}(\mathrm{Zn}) ; 20 \times 0.5 \mathrm{~mm}, \sim 700^{\circ} \mathrm{C}\right)$ 
fact that the hydrogen atom used to form benzene from the benzoate presumably comes from the water retained by excess $\mathrm{NaOH}$ on the surface of the conductor after evaporation of the solvent. The relative amount of water present decreases with increasing sample size. The thermal fragmentation of benzoic acid- $d_{5}$ clearly shows (Figure 10) that the hydrogen atom in question originates from other benzoic acid molecules (12). The decreasing benzene formation at high benzoic acid concentration (Figure 9) is, therefore, due to competing recombination reactions.

With amino acids the structure of the pyrolysis fragments in general correlates closely with the structure of the starting material $(5,10)$. The thermal fragmentation of mixtures gives signals as expected from the simple addition of the sig- nals (10) from the chromatograms of the individual acids. Similar results are obtained in the fragmentation of peptides (10). At present this seems to be in contrast to the findings of Merritt (13). With a somewhat different technique he observes a fragmentation depending on the peptide linkage (13).

More detailed information about the mechanism of the fragmentation may be obtained using tracer techniques. The arrangement given in Figure 11 shows the possibility of recording simultaneously the pyrolysis gas chromatograms as well as the pyrolysis radio gas chromatogram (14) of $\mathrm{C}^{14}$ - and $\mathrm{H}^{3}$-labelled compounds. The results obtained for labelled phenylalanine are presented in Figure 12. Several conclusions are possible using this information: The aromatic nucleus is fragmented to only a negligible ex- tent. The bond between the carbon atom 3 and the aromatic nucleus remains almost intact (12), in contrast to the bond between $C_{2}$ and $\mathrm{C}_{3}$. A considerably more complicated situation is shown in Figure 13 for the fragmentation of methionine (12).

In certain instances there is a parallel between the thermal fragmentation and the fragmentation induced by electron impact. Figure 14 shows schematically the pyrolysis gas chromatogram obtained in the fragmentation of o-nitrophenylhydrazone of anisaldehyde (12). The most interesting fragment formed is anisaldehyde. No aldehyde is observed in the pyrolysis of the corresponding phenylhydrazone; but it is, however, obtained in the thermal fragmentation of 2,4-dinitrostilbene (Figure 15). The results can be rationalized assum-

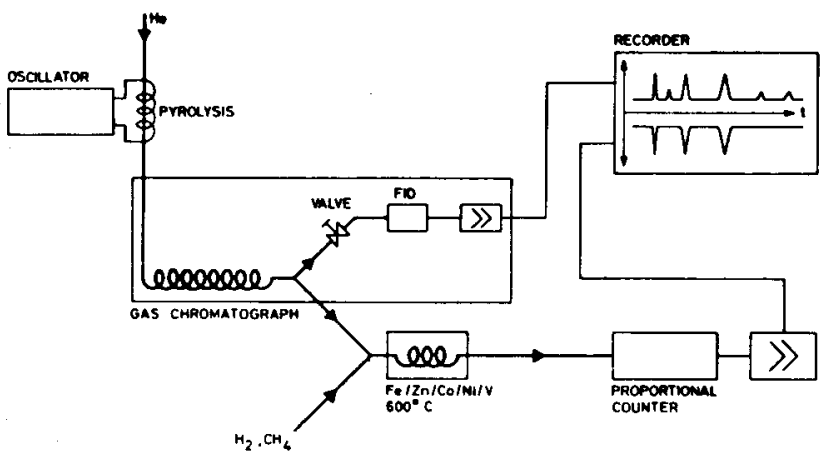

Figure 11. Instrumental Combination of Pyrolysis and Radio Gas Chromatography

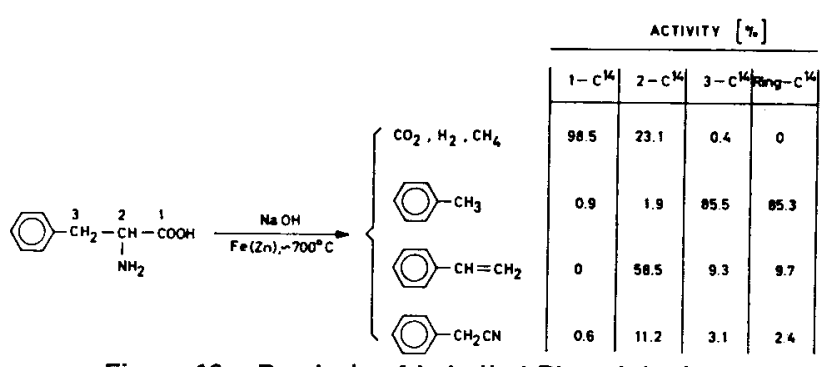

Figure 12. Pyrolysis of Labelled Phenylalanine

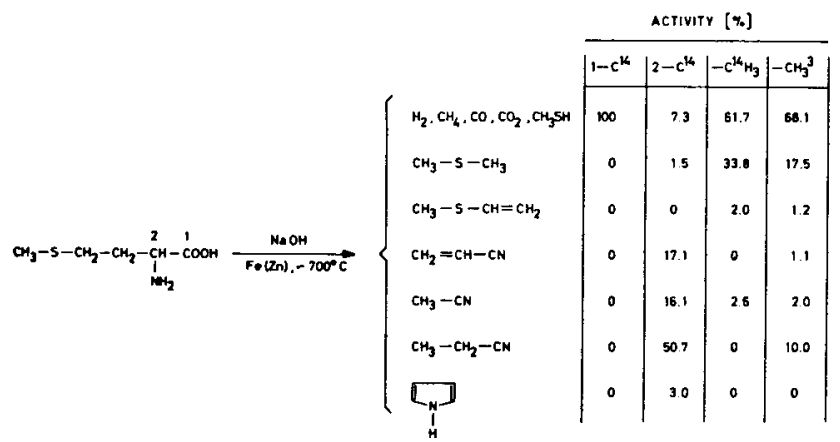

Figure 13. Pyrolysis of Labelled Methionine

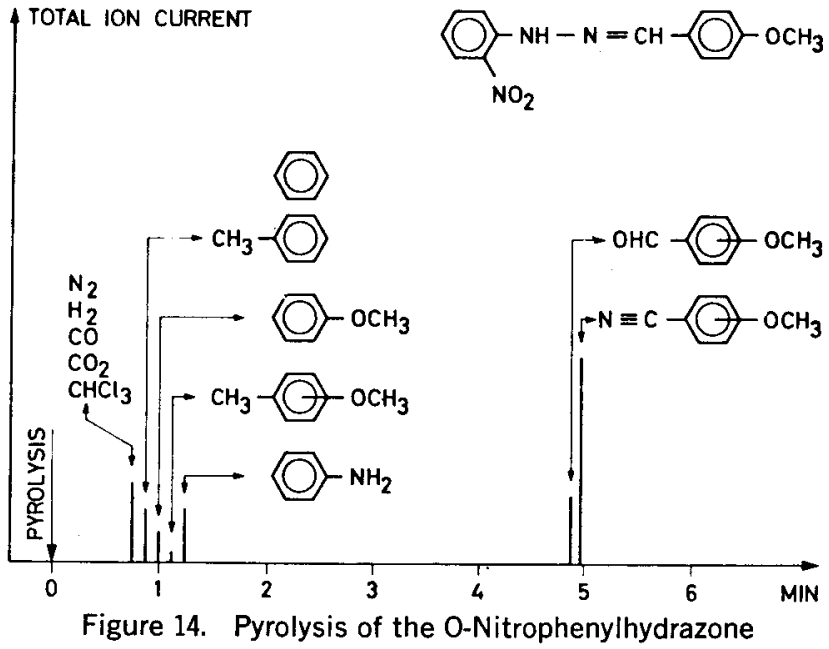

of Anisaldehyde

Ferromagnetic conductor: $\mathrm{Fe}(\mathrm{Zn}) ; \sim 700^{\circ} \mathrm{C} ; 20 \times 0.5 \mathrm{~mm}$.

GLC: FS 1265 (100 ft.; 0.02 in.); $150^{\circ} \mathrm{C}$

$12 \mathrm{ml} \mathrm{He} / \mathrm{min}$.

O-Nitrophenylhydrazone: $10 \%$ solution in $\mathrm{CHCl}_{3}$ used to coat the conductor.

MS: Hitachi Perkin-Elmer RMU-6D

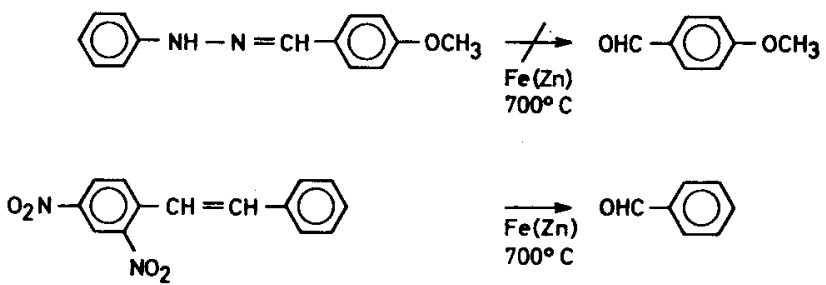

Figure 15. Thermal Fragmentation of Dinitrostilbene and the Phenylhydrazone of Anisaidehyde 


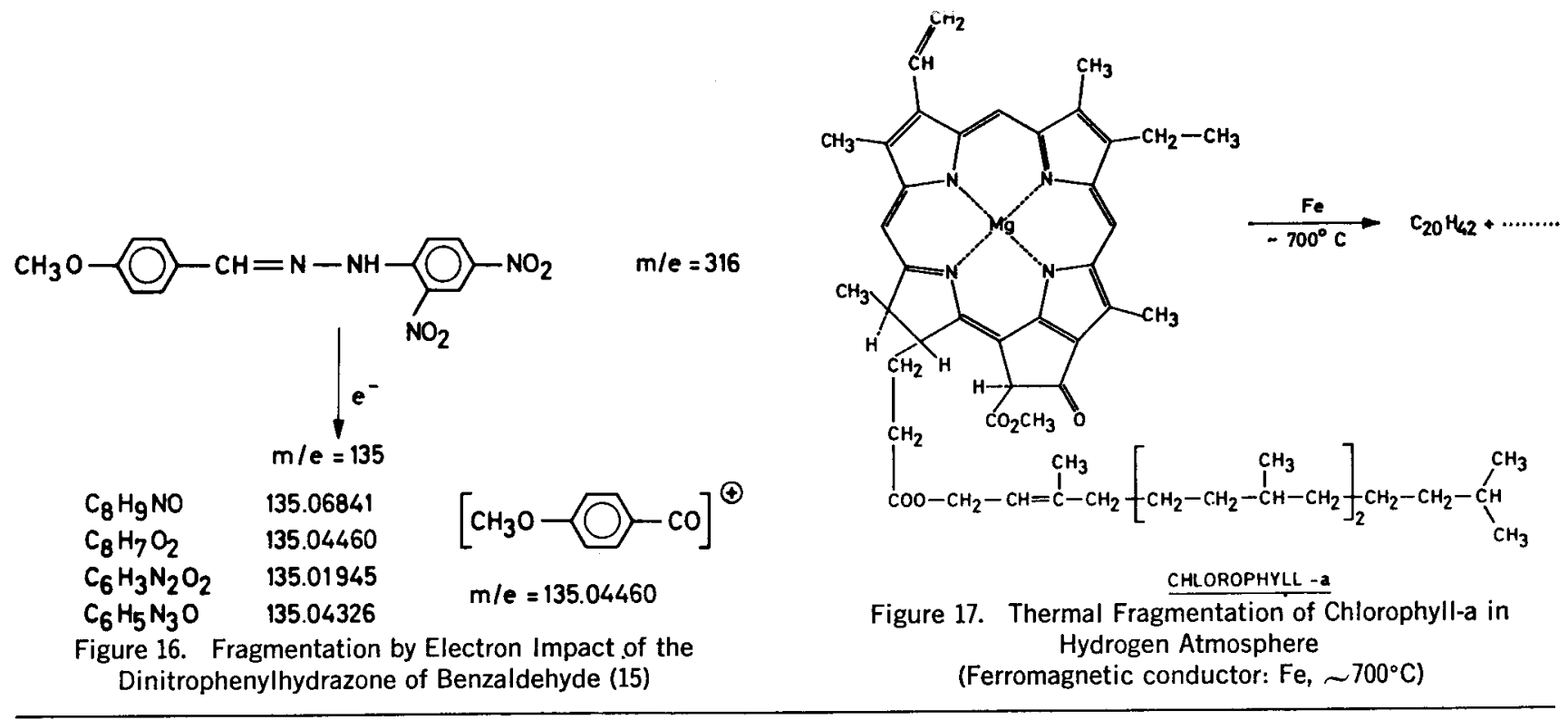

ing that a transfer of an oxygen atom of the nitro group has taken place. A similar rearrangement is observed in the corresponding mass spectra (Figure 16) (15). High resolution mass spectroscopy has shown that an electron impact fragment of mass number 135.04460 corresponding to $\mathrm{C}_{8} \mathrm{H}_{7} \mathrm{O}_{2}$ is obtained (15).

Since in mass spectrometry rearrangement reactions such as the McLafferty rearrangement (16) are quite common and since even ion molecule reactions are observed very frequently $(17,18)$, it is expected that thermal fragmentation reactions will be much more complex. This is mainly due to the fact that component concentrations are usually much higher than in mass spectrometry.

The application of the technique described is of course especially attractive for the study of compounds of high complexity which are difficult to study by other techniques (Figure 17) $(19,20)$.

The examples given show that the pyrolysis technique described has potentialities for the elucidation of the structure of organic compounds (20-24). A more detailed understanding of the mechanism of the fragmentation is needed for the successful application of this method. Because of the complexity of the fragmentation process, pyrolysis techniques may give information not obtained in electron impact fragmentation $(21,22)$. At present the method seems to be particularly attractive for compounds not acces- sible to mass spectrometry.

\section{Acknowledgment}

The present work has been supported by the Schweizerischer Nationalfonds zur Foorderung der wissenschaftlichen Forschung (Research Project No. 3602) and the Eidg. Volkswirtschafts-Stiftung.

\section{Literature Cited}

1. Diels, O., Gaedke, W., and Koerding, P., Ann. 459, 1 (1927).

2. Kokes, R. J., Tobin Jr., H., and Em- mett, P. H., J. Amer. Chem. Soc. 77, 5860 (1955).

3. Reiner, E., Symposium on Pyrolysis and Reaction Gas Chromatography, Ecole Polytechnique, September 1516, 1966, Paris.

4. Oyama, V. I., Symposium on Pyrolysis and Reaction Gas Chromatography, Ecole Polytechnique, September 15-16, 1966, Paris.

5. Simon, W., and Giacobbo, H., Chem.Ing.-Techn. 37, 709 (1965); Simon, W., and Giacobbo, H., Angew. Chem. int. Ed. 4, 938 (1965).

6. Levy, R. L., Symposium on Pyrolysis and Reaction Gas Chromatography, Ecole Polytechnique, September 1516, 1966, Paris.

7. Giacobbo, H., and Simon, W., Pharm. Acta Helv. 39, 162 (1964); Giacobbo, $H$. , and Simon, W., in Festschrift zum 60. Geburtstag von Jakbo Buechi (X. Perlia, Ed.), Verlag Schweizer Apothekerverein, Zurich, 1963, S. 199.

8. Jones, C. E. R., Moyles, A. F., Nature 191, 663 (1961); 189, 222 (1961).

9. Lehmann, F. A., and Brauer, G. M., Anal. Chem. 33, 673 (1961).
10. Voellmin, J. A., Kriemler, P., Omura, I., Seibl, J., and Simon, W., Microchem. J. 11, 73 (1966).

11. Voellmin, J. A., Omura, I., Seibl, J., Grob, K., and Simon, W., Helv. 49, 1768 (1966).

12. Kriemler, P., Voellmin, J. A., and Simon, W., Helv., in preparation.

13. Merritt Jr., C., and Robertson, D. H., Symposium on Pyrolysis and Reaction Gas Chromatography, Ecole Polytechnique, September 15-16, 1966, Pariş.

14. Simon, H., Muellhofer, G., and Medina, R., "Radioisotope Sample Measurement Techniques in Medicine and Biology," International Atomic Energy Agency, Vienna, 1965.

15. Seibl, J., private communication.

16. McLafferty, F. W., Appl. Spectroscopy 11, 148 (1957); Anal. Chem. 31, 82 (1959).

17. Biemann, K., Mass Spectrometry Organic Chemical Applications, McGraw-Hill Book Company, Inc., New York, San Francisco, Toronto, London, 1962.

18. Brown, P., Djerassi, C., Schroll, G., Jakobsen, H. J., and Lawesson, S. O., J. Amer. Chem. Soc. 87, 4559 (1965).

19. Whitten, D. G., Bentley, K. E., and Kuwada, D., J. Org. Chem. 31, 322 (1966).

20. Levy, R. L., Gesser, H., Halevi, E. A., and Saidman, S., J. Gas Chromatog. 2, 254 (1964).

21. Brauer, G. M., Journal of Polymer Science 8, 3 (1965).

22. Keulemans, A. I. M., Symposium on Pyrolysis and Reaction Gas Chromatography, Ecole Polytechnique, September 15-16, 1966, Paris.

23. Janak, J., Nature 185, 684 (1960).

24. Dhont, J. H., Nature 200, 882 (1963); Analyst 89, 71 (1964).

Manuscript received November 18, 1966 